\title{
All-in-one synthesis of mesoporous silicon nanosheets from natural clay and their applicability to hydrogen evolution
}

\author{
Jaegeon Ryu ${ }^{1,3}$, Youn Jeong Jang ${ }^{2,3}$, Sinho Choi ${ }^{1}$, Hyun Joon Kang ${ }^{2}$, Hyungmin Park ${ }^{1}$, Jae Sung Lee ${ }^{1}$ \\ and Soojin Park ${ }^{1}$
}

Silicon nanosheets have attracted much attention owing to their novel electronic and optical properties and compatibility with existing silicon technology. However, a cost-effective and scalable technique for synthesizing these nanosheets remains elusive. Here, we report a novel strategy for producing silicon nanosheets on a large scale through the simultaneous molten-salt-induced exfoliation and chemical reduction of natural clay. The silicon nanosheets thus synthesized have a high surface area, are ultrathin $(\sim 5 \mathrm{~nm})$ and contain mesoporous structures derived from the oxygen vacancies in the clay. These advantages make the nanosheets a highly suitable photocatalyst with an exceptionally high activity for the generation of hydrogen from a water-methanol mixture. Further, when the silicon nanosheets are combined with platinum as a cocatalyst, they exhibit high activity in $\mathrm{KOH}\left(15.83 \mathrm{mmol} \mathrm{H}_{2}\right.$ per s per $\left.\mathrm{mol} \mathrm{Si}\right)$ and excellent photocatalytic activity with respect to the evolution of hydrogen from a water-methanol mixture $\left(723 \mu \mathrm{mol} \mathrm{H}_{2}\right.$ per h per $\left.\mathrm{g} \mathrm{Si}\right)$.

NPG Asia Materials (2016) 8, e248; doi:10.1038/am.2016.35; published online 25 March 2016

\section{INTRODUCTION}

Recently, the development of clean and renewable energy sources has been pursued as a result of limited natural fuel resources and environmental pollution problems caused by fuel combustion. Hydrogen is a promising alternative energy source with its high energy density, cleanliness and storability. Hydrogen production with the solar-driven water reduction system, which uses infinite solar energy and water, has been studied extensively. ${ }^{1,2}$ Silicon has been exploited as an attractive candidate for solar hydrogen production due to its great natural abundance, straightforward processing and high efficiency. Nanostructured silicon (for example, nanowires, nanotubes and porous structures) fabricated from p-type silicon wafers and the modification of its surface have been suggested for photoelectrochemical (PEC) water reduction. ${ }^{3-10}$ Nevertheless, high hydrogen production efficiency, the complicated fabrication steps using silicon wafers and operating conditions (for example, use of an external bias and comprising circuit) remain challenges for practical application. Direct solar water reduction from a dispersed photocatalyst is a well-known, cost-effective and simple process.

Direct solar water reduction using silicon-based materials is still an untapped area due to the intrinsic instabilities of silicon-based materials in aqueous solution via oxide formation. Silicon dioxide layers reduce the performance by blocking photo-generated carrier transfer from the photocatalyst to the electron accepter. Meanwhile, Dai et al. ${ }^{11}$ synthesized nanosized mesoporous crystalline Si powders using an unconventional approach, namely, the bottom-up selftemplating method. These mesoporous crystalline Si powders showed an extremely high hydrogen evolution reaction (HER) activity in both a $\mathrm{KOH}$ etching system $\left(1.33 \mathrm{~mol} \mathrm{H}_{2}\right.$ per s per mol Si) and a solar water reduction system with methanol sacrificial reagent $\left(882 \mu \mathrm{mol} \mathrm{H}_{2}\right.$ per $\mathrm{h}$ per $\mathrm{g} \mathrm{Si}$ ) under a $300 \mathrm{~W}$ xenon light. ${ }^{11}$ Among the various nanostructured $\mathrm{Si}$ materials available, two-dimensional (2D) $\mathrm{Si}$ nanosheets (SiNSs) are desirable as a photocatalyst for the hydrogen evolution reaction based on several advantages such as high surface area, facile accessibility of water molecules and compatibility with other exceptional 2D supports or cocatalysts.

Numerous efforts have been devoted to synthesizing 2D SiNSs using a variety of methods. ${ }^{11-14}$ For instance, Okamoto et al. ${ }^{11,12}$ demonstrated that organosilicon $\left(\mathrm{Si}_{6} \mathrm{H}_{4} \mathrm{Ph}_{2}\right)$ nanosheets can be fabricated by the chemical reaction of polysilane $\left(\mathrm{Si}_{6} \mathrm{H}_{6}\right)$ and a Grignard reagent. This method is useful for forming regularly stacked structures of SiNSs with limited dimensions. However, this process cannot produce highly pure SiNSs on a large scale because the process involves metal doping or the use of methylamines. Recently, Kim et al. ${ }^{13}$ synthesized freestanding SiNSs through the chemical vapor deposition of $\mathrm{SiCl}_{4}$ on various substrates in a high-flux $\mathrm{H}_{2}$ environment without a catalyst

\footnotetext{
${ }^{1}$ Department of Energy Engineering, School of Energy and Chemical Engineering, Ulsan National Institute of Science and Technology (UNIST), Ulsan, South Korea and ${ }^{2}$ Department of Chemical Engineering, Pohang University of Science and Technology (POSTECH), Pohang, South Korea

${ }^{3}$ These authors contributed equally to this work.

Correspondence: Professor JS Lee or Professor S Park, Department of Energy Engineering, School of Energy and Chemical Engineering, Ulsan National Institute of Science and Technology (UNIST), UNIST-gil 50, Eonyang-eup, Ulju-gun, Ulsan 44919, South Korea.

E-mail: lee1234@unist.ac.kr or spark@unist.ac.kr

Received 14 October 2015; revised 8 January 2016; accepted 18 January 2016
} 
and observed a distinctive photoluminescence (PL) behavior. ${ }^{13}$ This gas-phase growth process, however, is limited because it produced SiNSs with a broad size distribution and thus is not suitable for costeffective large-scale production. A more scalable way of synthesizing SiNSs is to combine the ball milling of commercial sands with a magnesiothermic reduction. ${ }^{14}$ However, in spite of the simple nature of this process, the resulting SiNSs are almost all broken into small pieces and stacked in a large framework, limiting their use in various applications.

One strategy for synthesizing ultrathin SiNSs is to employ natural clays, which commonly exist as layered silicate structures. ${ }^{15}$ One such clay, montmorillonite (MMT), is a three-layered mineral consisting of a central octahedral (aluminum-oxygen) layer sandwiched between two tetrahedral (silicon-oxygen) layers. Chemical bonds between the shared interior oxide anions and the metal cations ( $\mathrm{Si}$ and $\mathrm{Al}$ ) link the layers, yielding unique nanosheet-like structures with an overall basal spacing of $\sim 2 \mathrm{~nm} .{ }^{15}$ Different natural clays contain different elements such as $\mathrm{Si}, \mathrm{Al}, \mathrm{Mg}, \mathrm{Fe}, \mathrm{Li}$ and $\mathrm{Na} \cdot{ }^{15,16}$ Most commercial clays exist as hundreds-of-micrometer-sized bulk particles stacked in the form of sheets. Thus, the clays must be exfoliated to obtain ultrathin sheets. Cation exchange between the interlocated metal cations and the bulk molecules (for example, long alkylamines and polymers, among others) and subsequent sonication is an established method for obtaining exfoliated clays consisting of only a few layers. ${ }^{17,18}$ Thus, natural clays with an ultrathin 2D structure can be employed for synthesizing thin SiNSs on a large scale.

Herein, we present an all-in-one strategy for the synthesis of highpurity SiNSs through the high-temperature molten salt (for example, $\mathrm{NaCl}$ )-induced exfoliation and simultaneous chemical reduction of clays. In this method, the metal salt serves two functions: it acts as a heat scavenger for the highly exothermic reduction reaction and as an exfoliation-inducing agent. The resulting SiNSs have a narrow size distribution (sizes of $1-5 \mu \mathrm{m}$ ) and are ultrathin (thickness of $\sim 5 \mathrm{~nm}$ ), owing to the penetration of the molten salt into the gallery of the clay. During the chemical reduction and the subsequent rinsing process, a mesoporous structure is formed within the SiNSs, resulting in the generation of specific surface areas as high as $300 \mathrm{~m}^{2} \mathrm{~g}^{-1}$. Furthermore, the SiNSs thus synthesized exhibit a photoassisted hydrogen production rate of $486 \mu \mathrm{mol} \mathrm{H}_{2}$ per h per g Si, owing to their large specific surface area and unique morphology. When the SiNSs are combined with Pt nanoparticles (NPs) as a cocatalyst, the hydrogen evolution rate increases significantly to $723 \mu \mathrm{mol} \mathrm{H}_{2}$ per h per g Si under visible light $(\lambda \geqslant 400 \mathrm{~nm})$; this rate is maintained for at least $26 \mathrm{~h}$ without significant degradation in the catalyst activity.

\section{MATERIALS AND METHODS}

\section{Synthesis of SiNSs}

MMT clay (15-35 wt $\%$ octadecylamine, Sigma-Aldrich, St Louis, MO, USA), magnesium powder (Sigma-Aldrich) and sodium chloride $(\mathrm{NaCl}$, Sigma-Aldrich) were mixed in a weight ratio of 1:0.7:3. This mixture was transferred to a stainless-steel reactor in an Ar atmosphere. Next, this reactor was placed in a tube furnace and heated to $550-700{ }^{\circ} \mathrm{C}$ for $5 \mathrm{~h}$. After the completion of the reaction, the resulting powder was dissolved in $100 \mathrm{ml}$ of deionized water under mild stirring for $3 \mathrm{~h}$ to remove the $\mathrm{NaCl}$. Then, $1 \mathrm{M} \mathrm{HCl}$ was added to this solution, and the solution was stirred at room temperature for $3 \mathrm{~h}$ to eliminate the by-product $\mathrm{MgO}$ and other possible impurities. Finally, the SiNSs were obtained by leaching with $0.2 \% \mathrm{HF}$, filtration and drying in vacuum at $80^{\circ} \mathrm{C}$ for $12 \mathrm{~h}$. The production yield of the SiNSs as synthesized was $\sim 40 \%$. Owing to their intrinsic affinity for moisture and light, the SiNSs were stored in a light-shielded container in an inert atmosphere.
Synthesis of SiNS-650/Pt. This synthesis follows the conventional platinumcoating process. The SiNS-650 sample was first immersed in $0.3 \mathrm{~m} \mathrm{HF}$ for $3 \mathrm{~min}$ to remove native oxides. Then, Pt NPs were deposited by immersing SiNS-650 into $0.3 \mathrm{M} \mathrm{HF}$ and $\mathrm{H}_{2} \mathrm{PtCl}_{6}$ solution for $3 \mathrm{~min}$. After rinsing with deionized water and drying, we could obtain Pt-decorated SiNS-650 (Supplementary Figure S9).

Synthesis of $m P$-SiNP. This synthesis follows the typical metal-assisted chemical etching process. In particular, $0.5 \mathrm{~g}$ of commercial Si NP (SiNP) ( $\geqslant 99.9 \%$ ca. $100 \mathrm{~nm}$, polycrystalline supplied by CNVISION, Seoul, South Korea) was mixed with $20 \mathrm{~mm} \mathrm{AgNO}_{3}$ aqueous solution for $10 \mathrm{~min}$. Then, a mixture of $2 \mathrm{M} \mathrm{HF}$ and $1.2 \%$ of $\mathrm{H}_{2} \mathrm{O}_{2}$ solution was added and stirred for an additional $30 \mathrm{~min}$. Finally, $5 \mathrm{M}$ of $\mathrm{HNO}_{3}$ solution was used to remove the $\mathrm{Ag}$ NPs at $50^{\circ} \mathrm{C}$ for $30 \mathrm{~min}$.

\section{Physical characterization}

Scanning electron microscopy (SEM, Verios 460, FEI, Hillsboro, OR, USA) was used to characterize the surface morphologies of the SiNS samples at an accelerating voltage of $10 \mathrm{kV}$ and a current of $0.4 \mathrm{nA}$. The dimensions and internal structures of the SiNSs were determined using transmission electron microscopy (TEM, JEOL-2100, JEOL Ltd., Tokyo, Japan) and high-resolution TEM (HRTEM, JEOL-2100C, JEOL Ltd.) at an accelerating voltage of $200 \mathrm{kV}$. To investigate the microstructures and degrees of crystallinity of the SiNS samples, X-ray diffraction (XRD) analyses (D8 ADVANCE, Bruker, Coventry, UK) were performed using $\mathrm{Cu}-\mathrm{K}_{\alpha}$ radiation $(\lambda=1.5418 \AA)$; Raman spectroscopy (alpha300R confocal microscope, WlTec, Ulm, Germany) was also employed for this purpose. The pore sizes and surface areas were characterized using a surface area and pore size analyzer (BELSORP-mini II, MicrotracBEL, Osaka, Japan) at $77 \mathrm{~K}$ for $\mathrm{P} / \mathrm{P}_{0}$ of $0.05-0.3$. X-ray photoelectron spectroscopy (XPS, Thermo Scientific Fishers K-alpha, Grange, UK) was used to perform surface elemental analyses. Further, the elemental components were confirmed using inductively coupled plasma mass spectrometry (ELAN DRC-II, PerkinElmer, Shelton, CT, USA). The thickness of the sheets of the SiNS-650 sample was measured using an atomic force microscopy system (Nanoscope III, Digital Instruments, Tonawanda, NY, USA) in the tapping mode.

\section{Photocatalytic hydrogen evolution}

The light-induced hydrogen production was estimated in an Ar-saturated aqueous solution containing methanol $(10 \mathrm{vol} \%, 100 \mathrm{ml})$ as a hole scavenger. The water/methanol mixture was purged with $\mathrm{Ar}$ for $2 \mathrm{~h}$, and $0.1 \mathrm{~g}$ of the $\mathrm{Si}$ photocatalyst being tested was added in a closed Pyrex glass vessel $(\sim 193.5 \mathrm{ml})$. The photocatalytic water-reduction reaction was performed under ambient conditions using a Xe lamp (300 W, Oriel, Irvine, CA, USA) equipped with an optical ultraviolet (UV) cut-off filter $(\lambda \geqslant 400 \mathrm{~nm})$ as a light source, with the mixture being subjected to mild stirring. Using $\mathrm{Ar}$ as the carrier gas, the amount of evolved $\mathrm{H}_{2}$ gas was detected by a gas chromatography (GC) system equipped with a thermal conductivity detector (HP 7890, molecular sieve $5 \AA$ column, Agilent, Santa Clara, CA, USA). To evaluate the long-term stability, the photocatalytic hydrogen evolution tests were performed for three cycles of $6 \mathrm{~h}$ each, with the light turned off in the interval for $2 \mathrm{~h}$ with Ar pulsing to remove the hydrogen produced in the previous cycle. The time-profiled hydrogen production from the stoichiometric etching of Si using $\mathrm{KOH}$ was also measured using gas chromatography. All the chemical reactions were performed in a $190 \mathrm{ml}$ glass flask with a tightly fitted rubber septum. The hydrogen production tests were repeated at least 10 times using a $1 \mathrm{~m}$ aqueous $\mathrm{KOH}$ solution.

\section{EIS measurements}

Electrodes of the four types of Si materials were fabricated by spreading a slurry mixture of the Si nanomaterial in question, polyvinylidene fluoride (10 wt $\%$ in $\mathrm{N}$-methyl-2-pyrrolidone, Sigma-Aldrich) and super P carbon black (weight ratio of 80:10:10) on a piece of $\mathrm{Cu}$ foil. The slurry was mixed with a mixer (ARE310, Thinky, Laguna Hills, CA, USA) at a high speed (2000 r.p.m.) for 10 min to ensure a homogeneous blend. After the slurry had been spread on the foil, it was dried at $110^{\circ} \mathrm{C}$ for $12 \mathrm{~h}$ in a vacuum oven. The ohmic contact was made using a $\mathrm{Cu}$ wire and $\mathrm{Ag}$ paste and the ohmic area was covered with resin. The exposed area of each electrode was $\sim 1 \mathrm{~cm}^{2}$. The Nyquist 


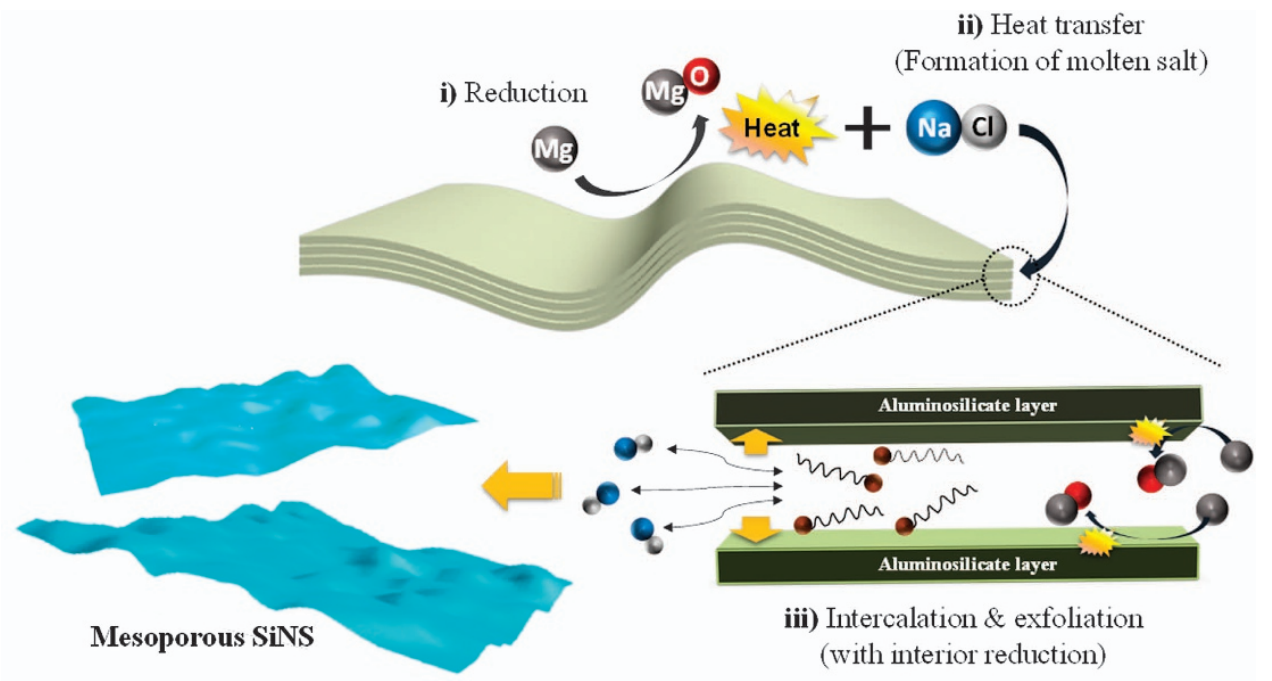

Figure 1 Schematic illustration showing the synthetic process for the preparation of SiNSs. Natural clay is exfoliated with molten NaCl. The exfoliated clay is then transformed into SiNSs by using Mg reductant. (i) Mg reduction process of clay minerals. (ii) Heat transfer process from reduction sites to metal salt $(\mathrm{NaCl})$, forming the molten salt. (iii) Intercalation and exfoliation process. Molten salts can be exchanged with intercalated alkylamines and metal cations inside clays. Then, $\mathrm{Mg}$ can reduce the interior of the clay minerals, generating additional heat to induce final exfoliation. SiNS, Si nanosheet.

electrochemical impedance spectroscopy (EIS) plots (applied voltage of $-0.2 \mathrm{~V}$ (vs $\mathrm{Ag} / \mathrm{AgCl}$ ), frequency range of $10^{-1}-10^{4} \mathrm{~Hz}$ ) were recorded using $0.5 \mathrm{M}$ $\mathrm{H}_{2} \mathrm{SO}_{4}$ as the electrolyte. The charge-transfer resistance and imperfect capacitance were determined by fitting an equivalent circuit to the data from the Nyquist EIS plots using the software ZSimpWin (Echem Software, Ann Arbor, MI, USA).

\section{Physicochemical characterization}

The optical properties of the $\mathrm{Si}$ nanomaterials were measured using a UV-visible diffuse reflectance spectrometer (UV-2401PC, Shimadzu, Tokyo, Japan) equipped with integrating spheres. The optical reflectances were recorded at room temperature for wavelengths of $200-1000 \mathrm{~nm} ; \mathrm{BaSO}_{4}$ was used as the reference. The position of the $\mathrm{Si}$ valence band was determined by UV photoelectron spectroscopy (UPS, ESCALAB 250Xi, monochromated Al$\mathrm{K}_{\alpha}$ radiation, Thermo Scientific, Grange, UK) under a base pressure of $10^{-10}$ torr. The PL spectra were measured using a fluorometer (Cary Eclipse, Agilent, Richardson, TX, USA). The excitation light had a wavelength of $400 \mathrm{~nm}$, and the observed PL emissions were in the range of 550-800 nm.

\section{RESULTS}

A schematic illustration for synthesizing SiNS via molten-salt-induced exfoliation of natural clays and the simultaneous chemical reduction of the exfoliated clays is shown in Figure 1. When the temperature of the system approaches the melting point of $\mathrm{Mg}$, solid $\mathrm{Mg}$ powders begin to be vaporized and adsorbed to the surface of adjacent clay minerals. Initially, $\mathrm{Mg}$ can react only on the exterior of the clay minerals. As the reaction proceeds, exothermic heat generated from the reduction reaction is transferred to the metal salt $(\mathrm{NaCl})$, which becomes molten. The activated molten salt can easily be intercalated into alkylamine-containing clays. Accordingly, $\mathrm{Mg}$ reacts with the interior surface of the clay. Heat generated from the interior space would accelerate the exfoliation of clays to produce the SiNSs evenly reduced from the clays. Preferentially, we conducted a careful investigation on the clay mineral. Commercially available MMT clay has a particle size distribution of $100 \mathrm{~nm}$ to $3 \mu \mathrm{m}$, as confirmed by SEM imaging (Supplementary Information (SI), Supplementary Figure S1A). The particles are stacked in the form of bilayers or multiple layers, as seen from the TEM images (SI, Supplementary Figures S1B and S1C) and the results of a high-power XRD analysis (SI, Supplementary
Figure S1E). Using thermal gravimetric analysis and Fourier transform infrared spectroscopy, we confirmed that long alkyl amines ( $30 \mathrm{wt} \%)$ were trapped in the gallery (SI, Supplementary Figures S2A and S2B). In addition, various metals such as $\mathrm{K}, \mathrm{Na}, \mathrm{Fe}$ and $\mathrm{Mg}$ are substituted for $\mathrm{Al}$ both in the clay lattice and in the interlayers in the form of hydroxides or hydrates (SI, Supplementary Figure S1D).

We subjected this MMT clay sample to molten-salt-induced exfoliation and simultaneous chemical reduction (herein, magnesiothermic reduction). The clay, which exists in a biphase of silicates and silica, was reacted with $\mathrm{Mg}$ vapor at $650^{\circ} \mathrm{C}$ (the melting temperature of $\mathrm{Mg}$ ) to produce the SiNSs. As expected, the magnesiothermic reaction generated a large amount of exothermic heat. Metal salts (for example, $\mathrm{NaCl}, \mathrm{KCl}$, and $\mathrm{MgCl}_{2}$ ) with a high melting point can be used as heat scavengers to reduce the exothermic heat. ${ }^{19,20} \mathrm{NaCl}$ was used as the metal salt in this system on the basis of the following criteria: (i) the melting point of $\mathrm{NaCl}\left(801^{\circ} \mathrm{C}\right)$ is much higher than the melting temperature of the metal reductant used $\left(\mathrm{Mg}=650^{\circ} \mathrm{C}\right)$, and (ii) MMT clay contains $\mathrm{Na}^{+}$cations and a small amount of alkylamines, which are exchangeable with $\mathrm{NaCl}$. If the metal salt used has a lower melting point than the metal reductant used, the salt will not be able to function as a heat scavenger. The clay sample is covered completely with an excess amount of the salt before the chemical reduction process starts. From the viewpoint of the cation-exchange process, monovalent cations with a smaller size can penetrate more readily into the highly ordered interlayers of the clay. For these reasons, $\mathrm{NaCl}$ is the most suitable metal salt for penetrating the clay gallery and reducing the amount of exothermic heat generated during the chemical reduction reaction.

When the MMT clay sample was reacted with $\mathrm{Mg}$ vapor at $650{ }^{\circ} \mathrm{C}$ for $5 \mathrm{~h}$ in the presence of $\mathrm{NaCl}$ as the heat scavenger (weight ratio of clay $/ \mathrm{Mg} / \mathrm{NaCl}=1: 0.7: 3$ ) and subsequently rinsed with concentrated $\mathrm{HCl}$, ultrathin SiNSs (referred to as SiNS-650) were obtained. As shown in the SEM image in Figure 2a, SiNS-650 exhibited a 2D nanosheet structure and did not show significant aggregation when compared with bare clay. Although SiNS-650 appeared to be stacked and aggregated, the frame size of the sheets was greatly reduced from a macroscopic perspective. In addition, SiNS-650 had a size on the order of tens of micrometers, attributable to the reconstruction of the Si 

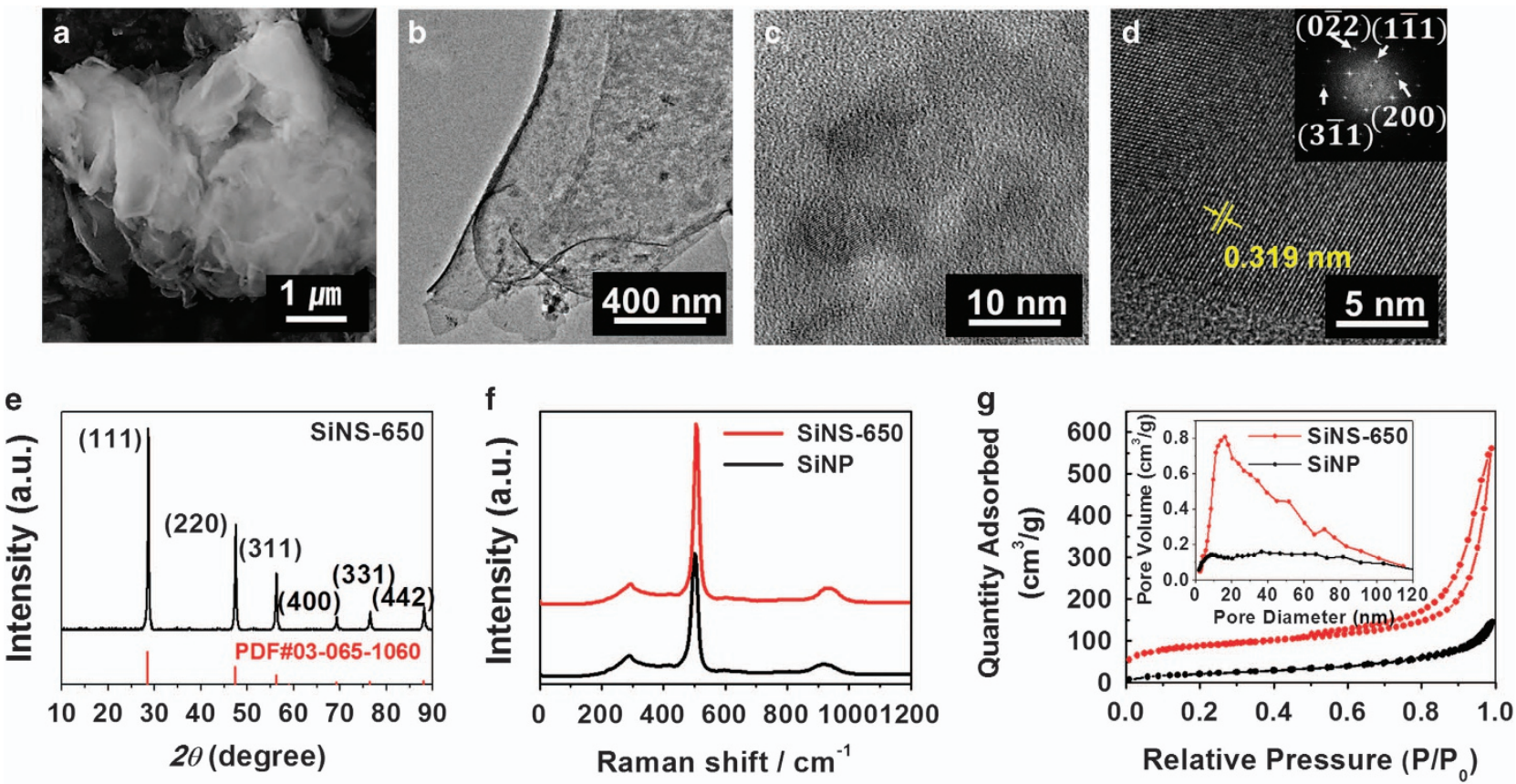

Figure 2 (a) SEM image, (b) TEM image, (c) HRTEM image, (d) magnified TEM image showing crystalline structure (inset: selected area electron diffraction pattern), (e) XRD pattern, (f) Raman spectrum and (g) nitrogen adsorption isotherms (inset: pore size distributions) of SiNS-650. Data for commercial Si nanoparticles (SiNPs) are shown in $\mathbf{f}$ and $\mathbf{g}$ for comparison. HRTEM, high-resolution transmission electron microscopy; SEM, scanning electron microscopy; SiNS, Si nanosheet; XRD, X-ray diffraction.

crystal structure from the silica and/or silicates. The by-product MgO, which was formed by the reaction between $\mathrm{Mg}$ and the oxygen in the silica/silicates, was removed completely by the $\mathrm{HCl}$ leaching process. A TEM image of the resulting SiNSs shows that mesoporous structures were uniformly distributed all over the SiNSs (Figures 2b and c). An HRTEM image of the SiNSs and the selected area electron diffraction pattern of the same indicated that highly crystalline Si was produced successfully (Figure 2d). Further, the HRTEM image showed that the crystallite size of SiNS-650 was $\sim 30-35 \mathrm{~nm}$, in good agreement with the value $(\sim 31 \mathrm{~nm})$ estimated from the XRD pattern (Figure $2 \mathrm{e})$ using the Scherrer equation. ${ }^{21}$ SiNPs were also confirmed to show a pure crystalline silicon phase with $\sim 3 \mathrm{~nm}$ size of crystallite forming a polycrystalline structure from the XRD pattern and TEM images (SI, Supplementary Figure S3). The selected area electron diffraction pattern (inset of Figure 2d) of SiNS-650 contained characteristics typical of polycrystalline $\mathrm{Si}$, which contains primarily the (111), (220) and (311) plane groups. The corresponding domain spacing value $(0.313 \mathrm{~nm})$ is well-matched with the value determined from the HRTEM analysis $(0.319 \mathrm{~nm})$. The Raman spectra of SiNS-650, shown in Figure $2 \mathrm{f}$, indicated that a sharp Si-related peak was located at a higher wavenumber $\left(508 \mathrm{~cm}^{-1}\right)$ than in the case of commercial SiNPs $\left(500 \mathrm{~cm}^{-1}\right)$. This result indicates that SiNS-650 had a higher crystallinity than commercial SiNPs. ${ }^{22}$

Furthermore, the mesoporous structure of SiNS-650 was confirmed from its nitrogen adsorption-desorption isotherms (Figure 2g). Its hysteresis loop showed a typical type-IV isotherm, ${ }^{23}$ indicating that mesopores were present within SiNS-650. Further, its Barrett-JoynerHalenda (BJH) pore-size distribution curve indicated that it had a broad pore size distribution, which ranged from 10 to $120 \mathrm{~nm}$, with the total pore volume being $0.86 \mathrm{~cm}^{3} \mathrm{~g}^{-1}$ (inset of Figure $2 \mathrm{~g}$ ). The minor portion of pores larger than $50 \mathrm{~nm}$ did not originate from the SiNS-650 itself but from the inter-area adsorption sites between the sheets. As shown in the SEM image (Figure 2a), SiNS, as synthesized, has a little crumbled and stacked structure with ultrathin SiNSs, resulting in many empty spaces for nitrogen-adsorption sites between the sheets. The Brunauer-Emmet-Teller (BET) surface area of SiNS-650 was $308 \mathrm{~m}^{2} \mathrm{~g}^{-1}$. In contrast, commercial SiNPs have a BET surface area of $\sim 80 \mathrm{~m}^{2} \mathrm{~g}^{-1}$ and have a nonporous structure (Figure $2 \mathrm{~g}$ ). The thickness of SiNS-650 was measured using atomic force microscopy (SI, Supplementary Figure S4A). Approximately 5-nm-thick ultrathin SiNSs were confirmed to have been synthesized successfully by the exfoliation of the MMT clay sample and its subsequent chemical reduction.

The properties of SiNSs are determined by the conditions for the exfoliation of the MMT clay and the chemical reduction reaction, including the reaction temperature, amount of metal salt used, reaction time and batch size, among other factors. Figure 3 shows the temperature-dependent morphological changes induced in the SiNSs. SiNS-550 (synthesized at a reaction temperature of $550{ }^{\circ} \mathrm{C}$ ) had a foam-like structure (Figures $3 \mathrm{a}-\mathrm{d}$ ). As seen in the SEM image in Figure $3 \mathrm{a}$, the overall particle size $(1-4 \mu \mathrm{m})$ was not significantly different from the overall particle size of the SiNS-650. However, the Si crystallite size was much smaller $(\sim 25 \mathrm{~nm})$. In contrast, SiNS-700 (synthesized at $700{ }^{\circ} \mathrm{C}$ ) was much larger, both microscopically ( $\mathrm{Si}$ crystallite size of $\sim 45 \mathrm{~nm}$, Figure $3 \mathrm{~h}$ ) and macroscopically $(2-7 \mu \mathrm{m}$, Figure $3 \mathrm{e})$. The crystallite sizes of the SiNS samples, as estimated from the HRTEM images, were consistent with the values (SiNS-550: $23 \mathrm{~nm}$ and SiNS-700: $43 \mathrm{~nm}$ ) calculated from their XRD patterns (Figure 4a).

Under optimized conditions (that is, in the case of SiNS-650), the exfoliation and chemical reduction of clay take place simultaneously. However, as the reaction temperature decreases to lower than the melting temperature of $\mathrm{Mg}$, the metal salt $(\mathrm{NaCl})$ has a higher priority in the reaction sequence. In other words, the metal salt covers almost the entire surface of the clay sample before the chemical reduction can start. Then, the partially vaporized $\mathrm{Mg}$ reacts preferentially with the 

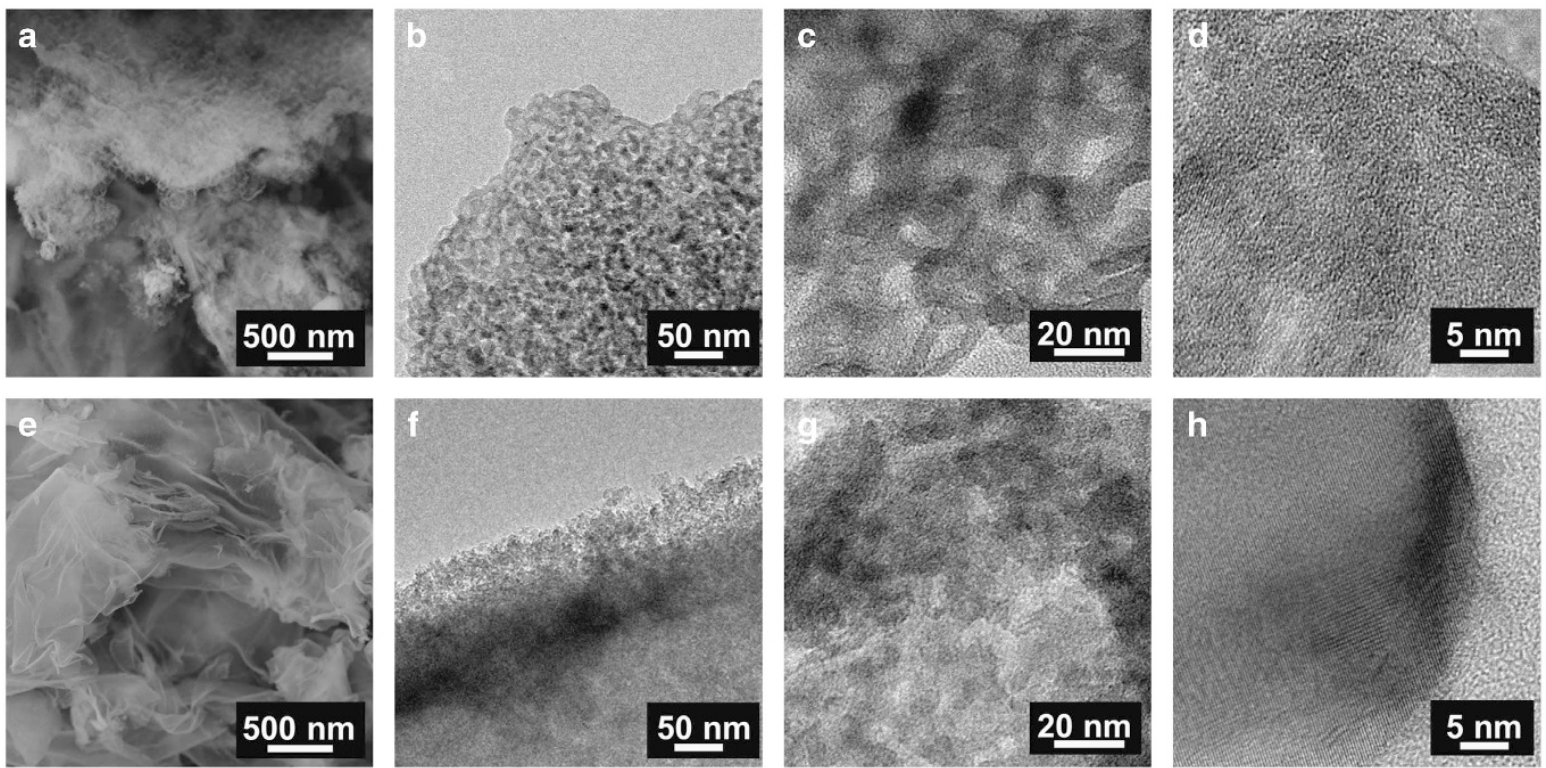

Figure 3 Characterization of the SiNS samples formed at different reaction temperatures. (a) SEM and (b-d) TEM images of SiNS-550. (e) SEM and ( $\mathbf{f}-\mathbf{h}$ ) TEM images of SiNS-700. SEM, scanning electron microscopy; SiNS, Si nanosheet; TEM, transmission electron microscopy.

a

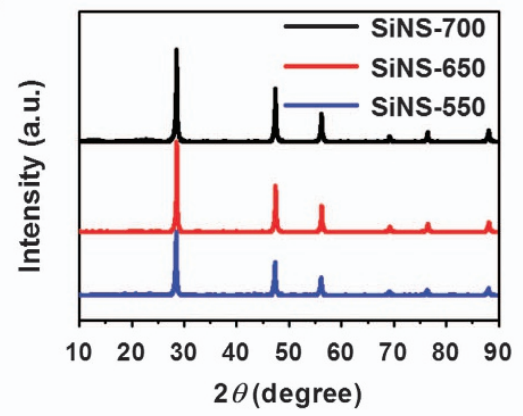

C

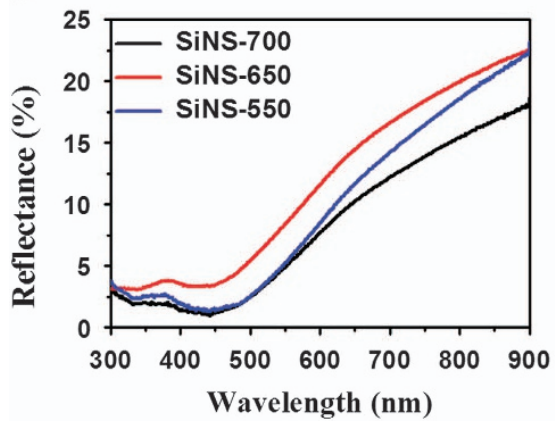

b

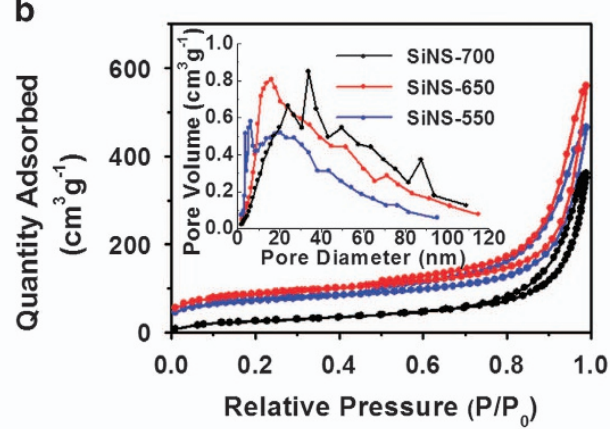

d

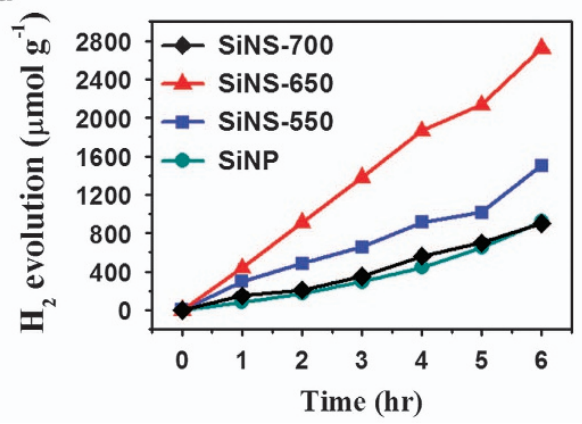

Figure 4 Characterization of the SiNS samples synthesized at different reaction temperatures. (a) XRD patterns, (b) nitrogen absorption-desorption isotherms (inset: pore size distributions), (c) Tauc plots and (d) amounts of hydrogen generated under visible-light illumination. SiNS, Si nanosheet; XRD, X-ray diffraction.

exposed clay surface. However, the reaction temperature is not sufficient to reduce the entire clay sample. Consequently, the degrees of exfoliation and chemical reduction are lowered, and the resulting products contain a large amount of oxygen (SI, Supplementary Figure S5). SiNS-550, which was synthesized at a low temperature, contained sponge-like structures with a broad pore size distribution (average pore size of $9.02 \mathrm{~nm}$ ) in the less-aggregated state (Figures $3 \mathrm{~b}$ and $\mathrm{c}$ ).
During the chemical reduction reaction, a large amount of thermal energy is transferred to the exfoliated clay, with the intercalation of the metal salt into the clay gallery occurring simultaneously. If either of these two processes does not take place, then exfoliation does not occur. From this perspective, the SEM image of SiNS-700 in Figure 3e shows that exfoliation occurred successfully. In contrast to SiNS-550 and SiNS-650, SiNS-700 exhibited a large number of nanopores (average pore size of $12.18 \mathrm{~nm}$ ), thicker sheets (SI, Supplementary 

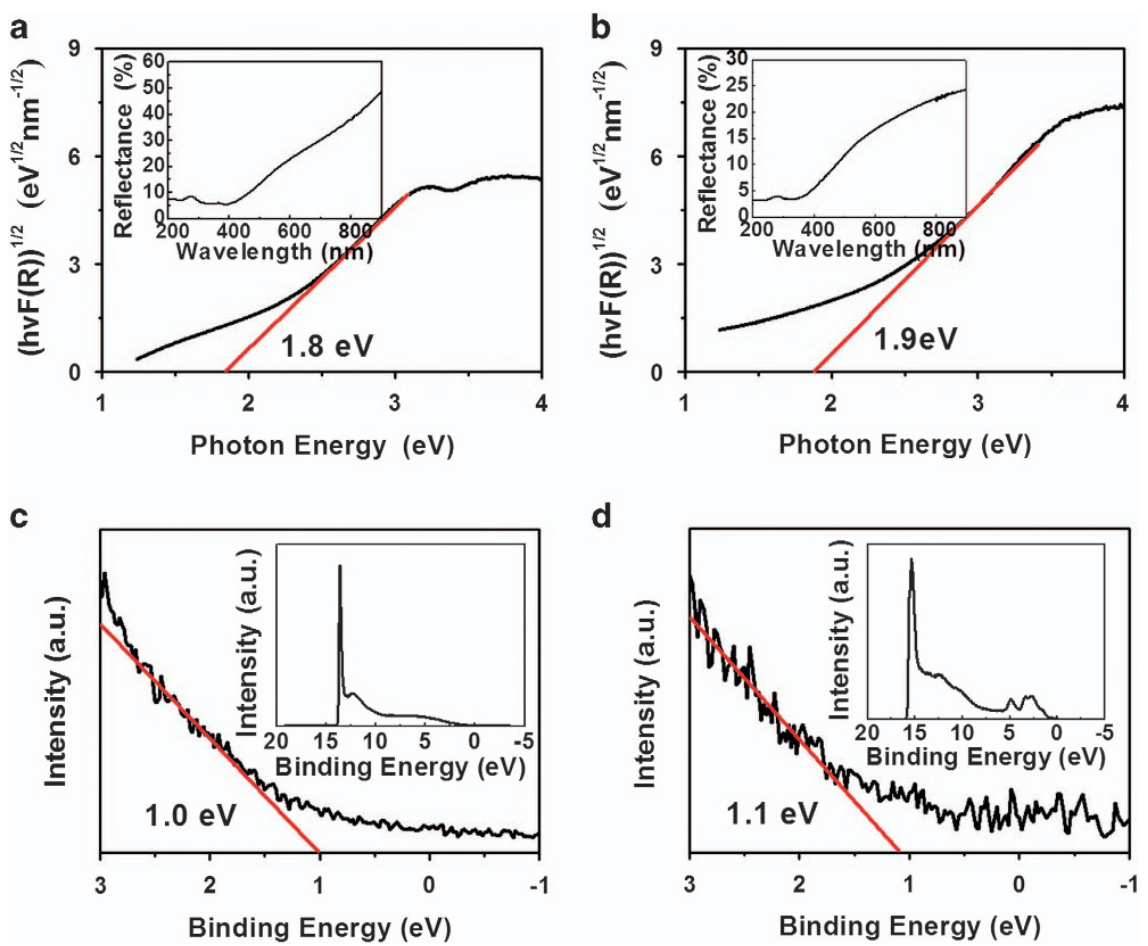

Figure 5 Tauc plots of (a) the SiNPs and (b) SiNS-650 (inset: UV-Vis diffuse reflectance spectra). UPS spectra of (c) the SiNPs and (d) SiNS-650 (inset: full-scan UPS spectrum). SiNP, Si nanoparticle; SiNS, Si nanosheet; UPS, UV photoelectron spectroscopy; UV, ultraviolet; Vis, visible; .

Figure S4B) and higher crystallinity (Figures $3 \mathrm{f}$ and g). Although the exfoliation of the clay sample and the chemical reduction reaction are synchronous processes, the release of an excess amount of thermal energy owing to the high reaction temperature causes aggregation, partial structural collapse and high crystallinity. Thus, the SiNS-700 was much larger, both microscopically (crystallite size of $\sim 45 \mathrm{~nm}$, Figure $3 \mathrm{~h}$ ) and macroscopically (sheet dimension of 2-7 $\mu \mathrm{m}$ ); this was consistent with the crystal size $(43 \mathrm{~nm})$ estimated from the XRD analysis (Figure 4a). These temperature-dependent variations in the sample structures (that is, degree of exfoliation) and reactivities (that is, degree of chemical reduction) are in line with the observations of the BET-specific surface areas and the $\mathrm{BJH}$ pore-size distributions (Figure $4 \mathrm{~b}$ ). In the case of SiNS-550, the MMT clay was not converted completely into pure SiNS. As a result, sponge-like structures with a low BET surface area $\left(215 \mathrm{~m}^{2} \mathrm{~g}^{-1}\right)$ were formed. In contrast, SiNS-700 contained a larger number of macropores, which caused it to have the lowest BET surface area $\left(170 \mathrm{~m}^{2} \mathrm{~g}^{-1}\right)$.

Further, we investigated the effects of the amount of salt used on the morphologies of the SiNSs at a fixed reaction temperature $\left(650^{\circ} \mathrm{C}\right)$ (SI, Supplementary Figures S6A-S6D). The introduction of even a small amount of the metal salt (weight ratio of clay $/ \mathrm{Mg} / \mathrm{NaCl}=1: 0.7: 0.5)$ during the chemical reduction process induced the exfoliation of the clay, resulting in the successful synthesis of the SiNSs. However, an upper limit exists for the amount of $\mathrm{NaCl}$ that can be used (weight ratio of clay/ $\mathrm{Mg} / \mathrm{NaCl}=1: 0.7: 5$ ) because the salt can hinder the chemical reduction process as shown in Supplementary Figures S6E and S6F. When the amount of $\mathrm{NaCl}$ used was varied while keeping the other conditions constant, including the reaction temperature $\left(650^{\circ} \mathrm{C}\right)$ and reaction time $(3 \mathrm{~h})$, the porosity of the SiNS formed was not affected significantly (SI, Supplementary Figure S6E). In addition, other variables such as the batch size and reaction time did not have a significant effect on the morphology and porosity of the SiNSs (SI, Supplementary Figure S7).
All the SiNS samples (SiNS-550, SiNS-650 and SiNS-700) exhibited similar light-absorbing properties, as shown in Figure 4c. However, the photocatalytic hydrogen evolution performances of the SiNS samples varied (Figure $4 \mathrm{~d}$ ). The amounts of hydrogen generated from a 10 vol $\% \mathrm{CH}_{3} \mathrm{OH}$-water mixture under visible-light illumination $(\lambda>400 \mathrm{~nm})$ for $6 \mathrm{~h}$ using SiNS-550, SiNS-650 and SiNS-700 were 233, 486 and $160 \mu \mathrm{mol} \mathrm{H}_{2}$ per h per g Si, respectively. All the SiNS samples exhibited hydrogen evolution rates significantly higher than the hydrogen evolution rates of commercial SiNPs $\left(153 \mu \mathrm{mol} \mathrm{H}_{2}\right.$ per $\mathrm{h}$ per $\mathrm{g} \mathrm{Si}$ ) for the same conditions. Of the various SiNS samples, the photocatalytic activity of SiNS-650 was the highest. This photocatalytic activity can be explained by the fact that (i) SiNS-650 consisted of ultrathin sheets (thickness of $\sim 5 \mathrm{~nm}$ ), which allowed for greater access for the reactants, (ii) SiNS-650 had a high specific surface area, which maximized the number of active sites, and (iii) SiNS-650 had a high crystallinity, which resulted in the effective separation of the photogenerated charge carriers. In contrast, the low crystallinity and incomplete reduction of SiNS-550 caused it to have poorer hydrogen evolution performance. Although SiNS-700 showed high crystallinity and a desirable sheet structure, its low specific surface area, which resulted from the aggregation of sheets, lowered the photocatalytic activity.

The band alignments of the commercial SiNPs and SiNS-650 were estimated from their Tauc plots and using UPS. ${ }^{7}$ Here, the optical band gap energies of SiNP and SiNS were calculated from Tauc plots according to the relationship $\alpha h v=A\left(h v-E_{\mathrm{g}}\right)^{2}$ or $\alpha h v=A\left(h v-E_{\mathrm{g}}\right)$ for the $3 \mathrm{D}$ SiNP and 2D SiNS, where $\alpha, h v, A$ and $E_{\mathrm{g}}$ are the absorption coefficient, the photon energy, a constant and the optical band gap energy ${ }^{24}$, respectively, as shown in Figures $5 \mathrm{a}$ and b. The estimated band gaps of the SiNPs $(1.8 \mathrm{eV})$ and SiNS-650 $(1.9 \mathrm{eV})$ are wider than the estimated band gaps of the bulk Si $(1.1-1.3 \mathrm{eV}){ }^{24}$ The wider band gaps of the Si nanomaterials can be attributed to the quantum confinement effect. ${ }^{25,26}$ The results of PL analysis, which is 

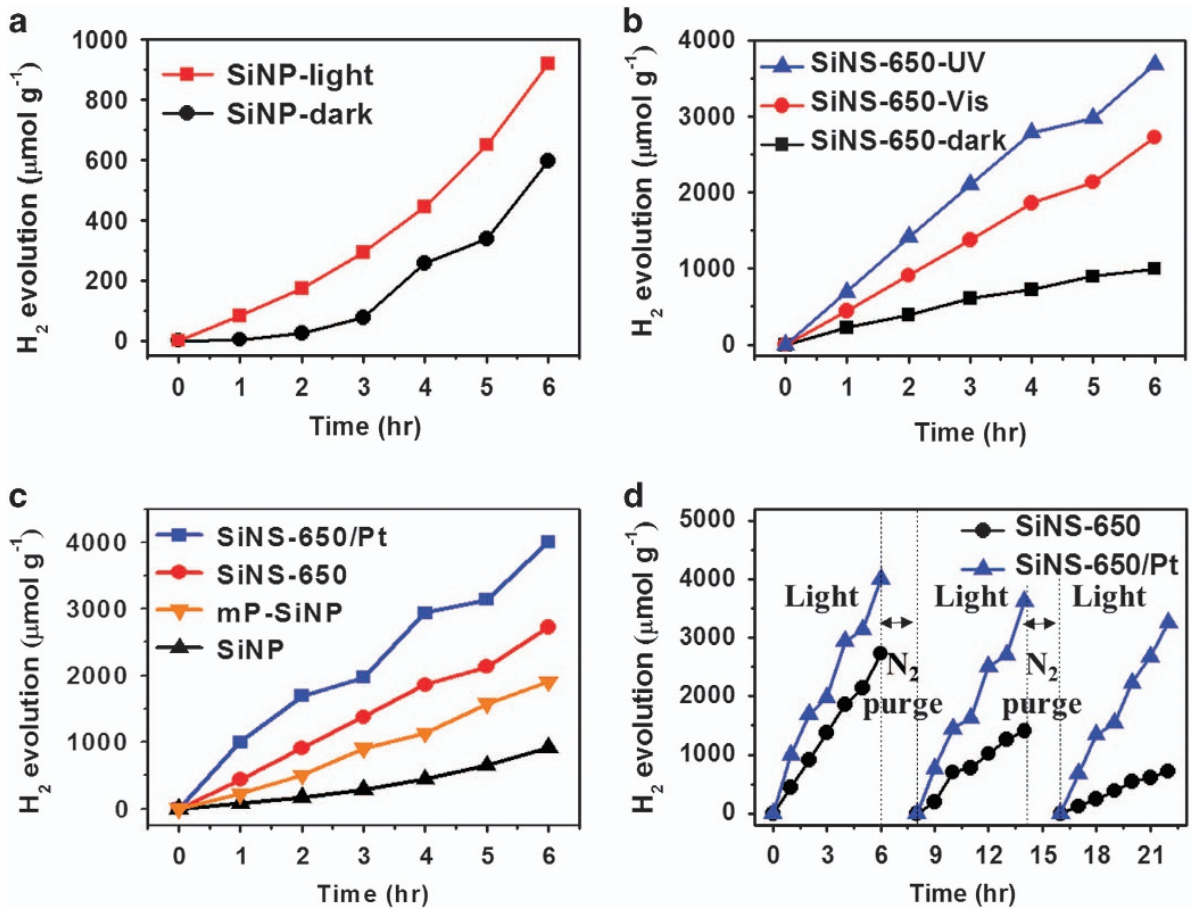

Figure 6 Photocatalytic performance. (a) Amounts of hydrogen generated using the SiNPs under visible-light illumination (red) and in dark (black). (b) Amounts of hydrogen generated using SiNS-650 under UV (blue) and visible-light (red) illumination and in dark (black). (c) Comparison of hydrogen production performance of Pt-decorated SiNS-650 (blue), SiNS-650 (red), mP-SiNPs (orange) and the SiNPs (black). (d) Stabilities of SiNS-650 and Pt-decorated SiNS-650 under visible-light illumination. SiNP, Si nanoparticle; SiNS, Si nanosheet; UV, ultraviolet.

discussed later, also confirmed that the band gaps were wider, owing to the quantum confinement effect. ${ }^{27,28}$ The positions of the valence bands of the SiNPs and SiNS-650, estimated using UPS, were $1.0 \mathrm{eV}$ and $1.1 \mathrm{eV}$, respectively (Figures $5 \mathrm{c}$ and $\mathrm{d}$ ). The band alignments of both the SiNPs and SiNS-650 were estimated using UPS and UV-visible absorption spectroscopy (SI, Supplementary Figure S8). ${ }^{29}$ Both the SiNPs and SiNS-650 were found to have highly negative conduction band edge potentials suitable for reducing water, even though the valence band positions were not positive enough to oxidize water.

The photocatalytic hydrogen evolution performance of SiNS-650 was investigated in more detail under visible-light illumination $(\lambda>400 \mathrm{~nm})$ while using $10 \mathrm{vol} \%$ methanol as a hole scavenger. SiNS-650 exhibited a higher activity with respect to the photoassisted production of hydrogen $\left(486 \mu \mathrm{mol} \mathrm{H}_{2}\right.$ per h per $\left.\mathrm{g} \mathrm{Si}\right)$ than did the commercially available SiNPs $(153 \mu \mathrm{mol} \mathrm{H}$ per h per g Si) (Figures 6a and c). The higher hydrogen production rate of SiNS-650 is attributable to its higher specific surface area, fewer defect sites and morphology, which maximized contact with the electrolyte. Si-based photocatalysts usually undergo a surface oxidation reaction because of the unstable dangling $\mathrm{H}$ bonds at the $\mathrm{Si}$ terminals under aqueous conditions (corresponding to dark conditions). ${ }^{30,31}$ In addition, when SiNS-650 was illuminated using UV radiation (without a cut-off filter), its hydrogen production rate increased markedly because of the extended supplying photon energy distribution (including the UV region) (Figure 6b).

Platinum is widely used as an electrocatalyst. When Pt is loaded onto a semiconductor photocatalyst, it forms a proton reduction center and facilitates the separation of the photogenerated charge carriers, thus improving the catalytic activity for the HER. Pt-decorated SiNS-650 (referred to as SiNS-650/Pt) shows a uniform distribution of $4 \mathrm{wt} \% \mathrm{Pt}$ NPs over the sheets with an average size of $\sim 10 \mathrm{~nm}$ (SI, Supplementary Figure S9). Thus, SiNS-650/Pt exhibited a significantly higher hydrogen production rate $\left(723 \mu \mathrm{mol} \mathrm{H}_{2}\right.$ per h per g Si) under visible-light illumination. The outstanding photocatalytic hydrogen production ability of SiNS materials is comparable to other Si-based materials and 2D semiconductor photocatalysts (Supplementary Table S1). Furthermore, SiNS-650/Pt maintained its activity for $26 \mathrm{~h}$ (three cycles; actual illumination period of $18 \mathrm{~h}$ ), as shown in Figure 6d. The deactivation of Si photocatalysts occurs because of the oxidation of their surfaces. ${ }^{5,32}$ In the case of a fresh $\mathrm{Si}$ surface, the dangling bonds on the surface readily form $\mathrm{Si}-\mathrm{H}$ species, which facilitate the separation of the photogenerated charge carriers, thus extending the carrier lifetime before recombination, and act as hydrogen production sites, where the electrons and protons can combine. ${ }^{33}$ The $\mathrm{Si}-\mathrm{OH}$ species formed by surface oxidation act as back reaction centers and form $\mathrm{H}_{2} \mathrm{O}$ with protons, the delivered electrons and the surface - $\mathrm{OH}$ groups.

To confirm whether this was indeed the deactivation mechanism of the Si-based catalysts, the Fourier transform infrared spectra of the SiNS-650 as prepared and used (for $26 \mathrm{~h}$ during the stability test) samples were measured (SI, Supplementary Figure S10). SiNS-650 contained $\mathrm{Si}-\mathrm{H}$ species on its surface; these species were derived from the HF treatment to which SiNS-650 was subjected during the refinement process. These $\mathrm{Si}-\mathrm{H}$ species were responsible for the stretching band observed at $2150-2050 \mathrm{~cm}^{-1}$ (SI, Supplementary Figure S10A) and the scissors-mode band at $\sim 910 \mathrm{~cm}^{-1}$ (SI, Supplementary Figure S10B). After SiNS-650 had been used for photocatalysis in an aqueous solution, the peak related to $\mathrm{Si}-\mathrm{H}$ disappeared, while a peak related to the $\mathrm{Si}-\mathrm{OH}$ vibrational mode was observed at $978 \mathrm{~cm}^{-1}$. Further, the broad band at $1275-1050 \mathrm{~cm}^{-1}$, attributable to the Si-O vibration modes, increased slightly in intensity. These results demonstrate that the surface oxidation of SiNS-650 was responsible for its deactivation as a 
photocatalyst. ${ }^{33-35}$ In addition, the Si $2 p$ XPS spectra of the SiNS-650 samples as prepared and used, as well as the spectra of SiNS-650/Pt were measured (SI, Supplementary Figure S11). Both SiNS-650 and SiNS-650/Pt exhibited two main XPS peaks at $104 \mathrm{eV}$ (attributable to $\left.\mathrm{Si}^{4+}\right)$ and at $99 \mathrm{eV}\left(\mathrm{Si}^{0}\right)$, respectively. After the long-term stability test, a broad peak was observed at $104 \mathrm{eV}$, indicating that the $\mathrm{Si}-\mathrm{H}$ species on the surface of the fresh SiNS-650 sample were oxidized in the water-splitting system. However, this change in the Si $2 p$ XPS spectrum was markedly suppressed in the case of SiNS-650/Pt, indicating that the Pt effectively protected the Si surface against oxidation. When the photocatalytic HER was performed in the absence of dark intervals, the amount of hydrogen generated increased almost linearly for $18 \mathrm{~h}$ (SI, Supplementary Figure S12). This result indicates that the surface oxidation of the catalysts occurred mainly in the dark periods.

\section{DISCUSSION}

It is important to determine how $\mathrm{NaCl}$ can actually affect the magnesiothermic system thermodynamically. We found that the temperature inside will be decreased greatly from $\sim 2200 \mathrm{~K}$ to $1100 \mathrm{~K}$ by introducing 3 equimolar amounts of $\mathrm{NaCl}$ from numerical computation results. This observation will be discussed in the thermodynamic consideration section of the SI in detail.

To investigate the reason for the different photocatalytic activities of SiNPs and SiNS-650, we conducted a comparative experiment to determine which factors, including structural effect and surface porosity, are dominant in this system. Even if the surfaces of both active materials were successfully modified into the $\mathrm{Si}-\mathrm{H}$-activated state, the SiNPs do not have enough surface area. Thus, mesoporous SiNPs were also prepared via a typical metal-assisted chemical etching process. ${ }^{36,37}$ Unlike the morphology of pristine SiNP (SI, Supplementary Figure S3A), mesoporous SiNPs as prepared have numerous mesopores on the surface (SI, Supplementary Figure S13A). However, BET analysis (SI, Supplementary Figure S13B) does not manifest a clear difference in surface area (both BET surface areas before and after etching were $\sim 80 \mathrm{~m}^{2} \mathrm{~g}^{-1}$ ). Thus, the SiNPs, which are of a size $<50 \mathrm{~nm}$, are quickly etched out at an early stage of the etching process. Unlike the pristine SiNPs, the pore size distribution shows the clear generation of mesopores centered at $\sim 10 \mathrm{~nm}$. When the photocatalytic hydrogen evolution performance of prepared mesoporous SiNPs is measured under the same conditions, its hydrogen production rate is remarkably increased to $356 \mu \mathrm{mol} \mathrm{H}_{2}$ per h per g Si (Figure 6c), which is comparable to the SiNS-650's value. However, SiNS-650 has the morphology of an ultrathin sheet, which brings easy accessibility to the electrolyte along with a large number of active sites, resulting in highly superior photocatalytic activity compared with SiNPs.

This logical aspect was further verified through potentiostatic EIS measurements using the same amounts of the active materials. The electrodes of the Si materials were held at $0 \mathrm{~V}_{\mathrm{RHE}}$, which was assumed to be the theoretical potential for the evolution of hydrogen under dark conditions. The Nyquist plots of the Si electrodes are shown in SI, Supplementary Figure S14. The impedance value of the SiNPs was greater than the impedance value of SiNS-650, indicating that the former had a larger resistance or fewer active sites. For further analysis, the EIS data were fitted using a simple equivalent circuit (SI, Supplementary Figure S14). The $R_{\mathrm{s}}$ value, that is, the left convergence point in the Nyquist plot, represents the sheet resistance of a half-cell test system. The values of the charge-transfer resistance and the constant phase element $\left(R_{\mathrm{ct}} / \mathrm{CPE}\right)$ are related to the properties of the catalysts. ${ }^{35}$ In the case of SiNS-650, $R_{\mathrm{ct}}$ was significantly lower (by a factor of $\sim 4.5$ ) than the $R_{\mathrm{ct}}$ of the SiNPs, while CPE was higher by a factor of $\sim 6.7$. The higher CPE value of SiNS-650, which was indicative of an imperfect capacitor, suggests an increase in surface heterogeneity and roughness, among other things. ${ }^{38}$ The actual active surface area of a catalyst can be qualitatively determined from the double-layer capacitance in a pure supporting electrolyte. The unique properties of SiNS-650, such as the presence of ultrafine pores and the desirable shape, which maximized contact with the electrolyte, were responsible for the high $\mathrm{CPE}$ value. This result is consistent with the high hydrogen production rate during the $\mathrm{KOH}$ etching of $\mathrm{Si}$ (SI, Supplementary Figure S15). Because hydrogen is generated from a stoichiometric reaction between $\mathrm{KOH}$ and the Si surface, the differences in the $\mathrm{KOH}$ etching rates are directly related to the differences in the active surface areas. The significantly higher hydrogen production rate of SiNS-650 (15.83 mmol $\mathrm{H}_{2} \mathrm{~s}^{-1} \mathrm{Si}$ $\mathrm{mol}^{-1}$ ) relative to the hydrogen production rate of the SiNPs ( $7.5 \mathrm{mmol} \mathrm{H}_{2} \mathrm{~s}^{-1} \mathrm{Si} \mathrm{mol}{ }^{-1}$ ) could be explained on the basis of the differences in the surface morphologies and surface-to-volume ratios of the two catalysts. ${ }^{30}$ In addition, because the crystallinity of SiNS-650 was higher than the crystallinity of the SiNPs (as shown in Figure 2d), a greater number of the photoderived electron-hole pairs were generated in the former case, with their separation and migration also being easier, owing to the lower $R_{\mathrm{ct}}$ value. ${ }^{11}$ In general, the $R_{\mathrm{ct}}$ value of a catalyst depends on the state of the catalyst. Low crystallinity and the presence of a large number of defect sites inhibit electron transfer and facilitate the recombination of the photogenerated electron-hole pairs. Further, the PL spectrum of the SiNPs showed an asymmetric and broad emission peak, indicating the presence of defect sites, which suppress charge transfer and separation as trap sites $^{39}$; this peak was not observed in the case of SiNS-650 (SI, Supplementary Figure S16). The symmetric and narrow PL spectrum of SiNS-650 is owed to the presence of fewer defect sites, as well as its high crystallinity, as was also indicated by its low $R_{\mathrm{ct}}$ value. On the basis of these facts, the reasons that the SiNS sample exhibited significantly higher photocatalytic activity compared to the SiNPs could be considered as follows: (i) the novel 2D sheet structure of the SiNS maximizes contact with the electrolyte, (ii) the large active surface area and mesopores allow easy access for the reactant, and (iii) the high crystallinity of $\mathrm{Si}$ and the presence of few defect sites promote the transfer/separation of photogenerated charge carriers and prevent their recombination.

In summary, the synthesized SiNSs are an attractive photocatalyst for water reduction and can be used for the photoassisted splitting of water in combination with other promising water oxidation photocatalysts (such as $\mathrm{BiVO}_{4}, \mathrm{TaON}$ and other n-type semiconductors) using the Z-scheme system. Furthermore, because of the abundance of the raw materials, the low fabrication cost and excellent hydrogen production performance, SiNSs have great potential for use as a photocathode material that compares favorably with other top-down-processed Si materials for PEC water-splitting systems. ${ }^{7,40}$

\section{CONFLICT OF INTEREST}

The authors declare no conflict of interest.

\section{ACKNOWLEDGEMENTS}

JSL was supported by the Korean Center for Artificial Photosynthesis (NRF-2011-C1AAA0001-2011-0030278), which is funded by MISIP, and through Project No. 10050509 of the Ministry of Trade, Industry and Energy (MOTIE), Republic of Korea. SP was supported by the Basic Science Research Program through the National Research Foundation of Korea funded by the Ministry of Science, ICT and Future Planning (NRF-2015-01003143). 
1 Turner, J. A. Sustainable hydrogen production. Science 305, 972-974 (2004).

2 Walter, M. G., Warren, E. L., McKone, J. R., Boettcher, S. W., Mi, Q., Santori, E. A. \& Lewis, N. S. Solar water splitting cells. Chem. Rev. 110, 6446-6473 (2010).

3 Goodey, A. P., Eichfeld, S. M., Lew, K.-K., Redwing, J. M. \& Mallouk, T. E. Silicon nanowire arrary photoelectrochemical cells. J. Am. Chem. Soc. 129, 12344-12345 (2007).

4 Oh, I., Kye, J. \& Hwang, S. Enhanced photoelectrochemical hydrogen production from silicon nanowire array photocathode. Nano Lett. 12, 298-302 (2012).

5 Liu, D., Li, L., Gao, Y., Wang, C., Jiang, J. \& Xiong, Y. The nature of photocatalytic "water splitting" on silicon nanowires. Angew. Chem. Int. Ed. 54, 2980-2985 (2015).

6 Boettcher, S. W., Spurgeon, J. M., Putnam, M. C., Warren, E. L., Turner-Evans, D. B., Kelzenberg, M. D., Maiolo, J. R., Atwater, H. A. \& Lewis, N. S. Energy-conversion properties of vapour-liquid-solid-grown silicon wire-array photocathodes. Science $\mathbf{3 2 7}$ 185-187 (2010)

7 Hou, Y., Abrams, B. L., Vesborg, P. C. K., Björketun, M. E., Herbst, K., Bech, L., Setti, A. M., Damsgaard, C. D., Pedersen, T., Hansen, O., Rossmeisl, J., Dahl, S., Nørskov, J. K. \& Chorkendorff, I. Bioinspired molecular co-catalysts bonded to a silicon photocathode for solar hydrogen evolution. Nat. Mater. 10, 434-438 (2011).

8 Chen, X., Lee, C.-S., Meng, X. \& Zhang, W. Diameter- and shape-controlled ZnS/S nanocables and Si nanotubes for SERS and photocatalytic Applications. J. Nanomater 2011, 830157 (2011)

9 Oh, J., Deutsch, T. G., Yuan, H.-C. \& Branz, H. M. Nanoporous black silicon photocathode for $\mathrm{H} 2$ production by photoelectrochemical water splitting. Energy. Environ. Sci. 4, 1690-1694 (2011).

$10 \mathrm{Ji}$, L., McDaniel, M. D., Wang, S., Posadas, B., Li, X., Huang, H., Lee, J. C., Demkov, A. A., Bard, A. J., Ekerdt, J. G. \& Yu, E. T. A silicon-based photocathode for water reduction with an epitaxial $\mathrm{SrTiO3}$ protection layer and a nanostructure catalyst. Nat. Nanotechnol. 10, 84-90 (2015).

11 Dai, F., Zai, J., Yi, R., Gordin, M. L., Sohn, H., Chen, S. \& Wang, D. Bottom-up synthesis of high surface area mesoporous crystalline silicon and evaluation of its hydrogen evolution performance. Nat. Commun. 5, 3605 (2014).

12 Sugiyama, Y., Okamoto, H., Mitsuoka, T., Morikawa, T., Nakanishi, K., Ohta, T. \& Nakano, H. Synthesis and optical properties of monolayer organosilicon nanosheets. J. Am. Chem. Soc. 132, 5946-5947 (2010).

13 Kim, S. W., Sung, J. H., Seo, D. J., Kim, I., Jo, M. H., Kwon, B. W., Choi, W. K. \& Choi, H. J. Two-dimensionally grown single-crystal silicon nanosheets with tunable visible-light emissions. ACS Nano 8, 6556-6562 (2014).

14 Kim, W.-S., Hwa, Y., Shin, J.-H., Yang, M., Sohn, H.-J. \& Hong, S.-H. Scalable synthesis of silicon nanosheets from sand as an anode for Li-ion batteries. Nanoscale 6 , 4297-4302 (2014).

15 Ray, S. S. \& Okamoto, M. Polymer/layered silicate nanocomposites: a review from preparation to processing. Prog. Polym. Sci. 28, 1539-1641 (2003).

16 Ogawa, M. \& Kuroda, K. Photofunctions of intercalation compounds. Chem. Rev. 95 399-438 (1995).

17 Uribe-Romo, F. J. \& Dichtel, W. R. Two-dimensional materials polymers stripped down. Nat. Chem. 4, 244-245 (2012)

18 Shau, S.-M., Juang, T.-Y., Ting, W.-H., Wu, M.-Y., Dai, S. A. \& Jeng, R.-J. Exfoliation of layered silicates through in situ controlled free radical polymerization mediated by a silicate-anchored initiator. Polym. Chem. 2, 2341-2349 (2011).

19 Bao, Z., Weatherspoon, M. R., Shian, S., Cai, Y., Graham, P. D., Allan, S. M., Ahmad, G., Dickerson, M. B., Church, B. C., Kang, Z., Abernathy, H. W. 3rd, Summers, C. J., Liu, M. \& Sandhage, K. H. Chemical reduction of three-dimensional silica micro-assemblies into microporous silicon replicas. Nature 446, 172-175 (2007).

20 Luo, W., Wang, X., Meyers, C., Wannenmacher, N., Sirisaksoontorn, W., Lerner, M. M., Lerner, M. M. \& Ji, X. Efficient fabrication of nanoporous Si and Si/Ge enabled by a heat scavenger in magnesiothermic reactions. Sci. Rep. 3, 2222 (2013).

21 Patterson, A. L. The Scherrer formula for X-ray particle size determination. Phys. Rev. 56, 978-982 (1939)

22 Parker, J. H., Feldman, D. W. \& Ashkin, M. Raman scattering by silicon and germanium. Phys. Rev. 155, 712-714 (1967).

23 Sing, K. S. W., Everett, D. H., Haul, R. A. W., Moscou, L., Pierotti, R. A., Rouquérol, J. \& Siemieniewska, T. Reporting physisorption data for gas solid systems with special reference to the determination of surface-area and porosity. Pure Appl. Chem. 57, 603-619 (1985).

24 Bianco, E., Butler, S., Jiang, S., Resprepo, O. D., Windl, W. \& Goldberger, J. E. Stability and exfoliation of germanane: a germanium graphane analogue. ACS Nano 7, 4414-4421 (2013).

25 Jang, H., Lee, W., Won, S. M., Ryu, S. Y., Lee, D., Koo, J. B., Ahn, S. D., Yang, C. W. Jo, M. H., Cho, J. H., Rogers, J. A. \& Ahn, J. H. Quantum confinement effects in transferrable silicon nanomembranes and their applications on unusual substrates. Nano Lett. 13, 5600-5607 (2013).

26 Delerue, C., Allan, G. \& Lannoo, M. Theoretical aspects of the luminescence of porous silicon. Phys. Rev. B 48, 11024-11036 (1993).

$27 \mathrm{Li}, \mathrm{M} ., \mathrm{Li}$, J. C. \& Jiang, Q. Size-dependent band-gap and dielectric constant of Si nanocrystals. Int. J. Mod. Phys. B 24, 2297-2301 (2010).

28 Kux, A. \& Chorin, M. B. Band-gap of porous silicon. Phys. Rev. B 51 17535-17541 (1995).

29 Cai, C.-F., Wu, H.-Z., Si, J.-X., Jin, S.-Q., Zhang, W.-H., Xu, Y. \& Zhu, J.-F. Energy band alignment of $\mathrm{PbTe} / \mathrm{CdTe}(111)$ interface determined by ultraviolet photoelectron spectra using synchrotron radiation. Chin. Phys. B 19, 077301 (2010).

30 Erogbogbo, F., Lin, T., Tucciarone, P. M., LaJoie, K. M., Lai, L., Patki, G. D., Prasad, P. N. \& Swihart, M. T. On-demand hydrogen generation using nanosilicon: splitting water without light, heat, or electricity. Nano Lett. 13 451-456 (2013).

31 Zhan, C., Chu, P. K., Ren, D., Xin, Y., Huo, K., Zou, Y. \& Huang, N. K. Release of hydrogen during transformation from porous silicon to silicon oxide at norma temperature. Int. J. Hydrogen Energy 36, 4513-4517 (2011).

32 Benck, J. D., Lee, S. C., Fong, K. D., Sinclair, R. \& Jaramillo, T. F. Designing active and stable silicon photocathodes for solar hydrogen production using molybdenum sulfide nanomaterials. Adv. Energy Mater. 4, 1400739 (2014).

33 Sun, X. H., Wang, S. D., Wong, N. B., Ma, D. D. D. \& Lee, S. T. FTIR spectroscopic studies of the stabilities and reactivities of hydrogen-terminated surfaces of silicon nanowires. Inorg. Chem. 42, 2398-2404 (2003).

34 Michalak, D. J., Amy, S. R., Esteve, A. \& Chabal, Y. J. Investigation of the chemical purity of silicon surfaces reacted with liquid methanol. J. Phys. Chem. C 112 11907-11919 (2008)

35 Morales-Guio, C. G. \& Hu, X. L. Amorphous molybdenum sulfides as hydrogen evolution catalysts. Acc. Chem. Res. 47, 2671-2681 (2014).

36 Bang, B. M., Kim, H., Lee, J.-P., Cho, J. \& Park, S. Mass production of uniform-sized nanoporous silicon nanowire anodes via block copolymer lithography. Energy Environ. Sci. 4, 3395-3399 (2011)

37 Bang, B. M., Lee, J.-I., Kim, H., Cho, J. \& Park, S. High-performance macroporous bulk silicon anodes synthesized by template-free chemical etching. Adv. Energy Mater. 2 , 878-883 (2012)

38 Mulder, W. H., Sluyters, J. H., Pajkossy, T. \& Nyikos, L. Tafel current at fractal electrodes - connection with admittance spectra. J. Electroanal. Chem. 285, 103-115 (1990).

39 Moubah, R., Schmerber, G., Rousseau, O., Colson, D. \& Viret, M. Photoluminescence investigation of defects and optical band gap in multiferroic $\mathrm{BiFeO} 3$ single crystals. Appl. Phys. Express 5, 035802 (2012).

40 Wang, Q., Hisatomi, T., Ma, S. S. K., Li, Y. \& Domen, K. Core/shell structured La- and Rh-codoped SrTiO3 as a hydrogen evolution photocatalyst in Z-scheme overall water splitting under visible light irradiation. Chem. Mater. 26, 4144-4150 (2014).

(i) This work is licensed under a Creative Commons Attribution 4.0 International License. The images or other third party material in this article are included in the article's Creative Commons license, unless indicated otherwise in the credit line; if the material is not included under the Creative Commons license, users will need to obtain permission from the license holder to reproduce the material. To view a copy of this license, visit http:// creativecommons.org/licenses/by/4.0/

Supplementary Information accompanies the paper on the NPG Asia Materials website (http://www.nature.com/am) 